\section{Correspondence on 'The use of tocilizumab and tofacitinib in patients with resolved hepatitis B infection: a case series'}

We read with great interest the article 'The use of tocilizumab and tofacitinib in patients with resolved hepatitis B infection: a case series' by Serling-Boyd et al. ${ }^{1}$ In this article, the authors conducted a retrospective study and examined the safety of tocilizumab (TCZ) and tofacitinib (TOF) in patients with resolved hepatitis B virus (HBV) infection defined as $\mathrm{HB}$ surface antigen (HBsAg)-negative, HB surface antibody (HBsAb)-positive and/or HB core antibody $(\mathrm{HBc} A b)$-positive status. According to the authors, none of the patients developed $\mathrm{HBV}$ reactivation, leading to the conclusion that TCZ and TOF may be safely used in patients with resolved HBV infection. ${ }^{1} \mathrm{HBV}$ reactivation can potentially cause de novo hepatitis $\mathrm{B}$ associated with a high mortality rate. ${ }^{2}$ Thus, this study is clinically relevant and reduces our anxiety regarding the management of HBV. However, we have several concerns about this report.

First, as acknowledged by the authors, it is difficult to draw any definitive conclusions owing to the small number of cases $(\mathrm{N}=20)$. In fact, we have encountered patients with rheumatoid arthritis who experienced HBV reactivation while receiving TCZ or TOF treatment. ${ }^{3}$ We and other groups have shown that, essentially, all types of biological or targeted synthetic disease-modifying antirheumatic drugs (b/tsDMARDs) are associated with a risk of HBV reactivation..$^{3-5}$ Although the reported incidence of HBV reactivation in patients with resolved $\mathrm{HBV}$ infection who were treated with $\mathrm{b} / \mathrm{tsDMARDs}$ is at most $5 \%-10 \%,{ }^{3-5}$ careful monitoring of HBVDNA is required in these patients.

Second, patients with chronic hepatitis B (HBsAg-positive) who are prescribed $b /$ tsDMARDs often receive concomitant treatment with antiviral drugs. However, there is paucity of evidence regarding the prophylactic administration of antiviral drugs in patients with resolved HBV infection who are treated with b/tsDMARDs. In this study, antivirals were prescribed for a quarter of patients with resolved HBV infection. ${ }^{1}$ Further studies are required to verify the cost-effectiveness of prophylactic administration of antivirals.

Third, the authors described that HBV-DNA or HBsAg were reassessed in $88 \%$ patients in the TCZ group and $75 \%$ patients in the TOF group after treatment initiation, meaning that HBVDNA was not monitored in all patients with resolved HBV infection. ${ }^{1}$ Three-quarters of people previously exposed to HBV reside in the Asia-Pacific region, ${ }^{6}$ while the estimated prevalence of HBV infection in North America is less than 2\%. Therefore, screening and monitoring for HBV reactivation should be more stringently performed in Asia. We have extensively worked on HBV infection in various rheumatic diseases, ${ }^{8-10}$ and recently proposed a multidisciplinary approach for prevention of HBV reactivation and subsequent de novo hepatitis B. ${ }^{3}$ The multidisciplinary team consists of medical staff (doctors, nurse, pharmacists and technicians) as well as personnel from the medical safety promotion office and medical information management office; monitoring of HBV screening and HBV-DNA testing is performed every 2 weeks. This approach has helped improve the HBV screening rate dramatically. ${ }^{3}$ Although the cost-effectiveness remains unclear, we believe that these efforts are important, particularly in the Asia-Pacific region.

Despite several limitations, this article successfully raised awareness of $\mathrm{HBV}$ reactivation. Drugs with novel mechanisms of action are rapidly emerging in the field of rheumatology. HBV reactivation should always be kept in mind in patients with chronic and resolved $\mathrm{HBV}$ infection.
Ryu Watanabe $\odot,{ }^{1}$ Motomu Hashimoto, ${ }^{1}$ Akio Morinobu ${ }^{2}$

${ }^{1}$ Department of Advanced Medicine for Rheumatic Diseases, Kyoto University Graduate School of Medicine, Kyoto, Japan

${ }^{2}$ Department of Rheumatology and Clinical Immunology, Kyoto University Graduate School of Medicine, Kyoto, Japan

Correspondence to Dr Ryu Watanabe, Department of Advanced Medicine for Rheumatic Diseases, Kyoto University Graduate School of Medicine, Kyoto 606-8507, Japan; ryuwatanabe@kuhp.kyoto-u.ac.jp

Contributors RW wrote the manuscript. MH and AM revised and finalised the manuscript.

Funding The authors have not declared a specific grant for this research from any funding agency in the public, commercial or not-for-profit sectors.

Competing interests Department of Advanced Medicine for Rheumatic Diseases is supported by Nagahama City, Shiga, Japan, Toyooka City, Hyogo, Japan, and five pharmaceutical companies (Mitsubishi Tanabe Pharma Co., Chugai Pharmaceutical Co. Ltd, UCB Japan Co. Ltd, AYUMI Pharmaceutical Co. and Asahi Kasei Pharma Corp.). It is also supported by grant from Daiichi Sankyo Co. Ltd. RW has received speaker's fee from Mitsubishi Tanabe, Pfizer, Sanofi, AbbVie, Asahi Kasei, Eisai, Eli Lilly, Bristol-Myers Squibb and Janssen. MH received a research grant and/or speaker fee from Bristol-Myers, Eisai, Eli Lilly and Mitsubishi Tanabe Pharma. AM has received speaking fees and/or research grants from Eli Lilly Japan K.K., Ono Pharmaceutical Co., Pfizer Inc., UCB Japan, AbbVie G.K., Asahi Kasei Pharma and Chugai Pharmaceutical Co. Ltd. The above-mentioned pharmaceutical companies were not involved in this correspondence at any process.

Patient and public involvement Patients and/or the public were not involved in the design, or conduct, or reporting or dissemination plans of this research.

Patient consent for publication Not required.

Provenance and peer review Not commissioned; internally peer reviewed.

(C) Author(s) (or their employer(s)) 2020. No commercial re-use. See rights and permissions. Published by BMJ.

\section{Check for updates}

To cite Watanabe R, Hashimoto M, Morinobu A. Ann Rheum Dis Epub ahead of print: [please include Day Month Year]. doi:10.1136/annrheumdis-2020-219270

Received 9 October 2020

Accepted 11 October 2020

Ann Rheum Dis 2020;0:1. doi:10.1136/annrheumdis-2020-219270

ORCID iD

Ryu Watanabe http://orcid.org/0000-0002-1089-5296

\section{REFERENCES}

1 Serling-Boyd N, Mohareb AM, Kim AY, et al. The use of tocilizumab and tofacitinib in patients with resolved hepatitis B infection: a case series. Ann Rheum Dis 2020:annrheumdis-2020-218289.

2 Loomba R, Liang TJ. Hepatitis B reactivation associated with immune suppressive and biological modifier therapies: current concepts, management strategies, and future directions. Gastroenterology 2017;152:1297-309.

3 Watanabe R, Igarashi T, Takahashi T, et al. Multidisciplinary approach to prevent de novo hepatitis B in patients with rheumatoid arthritis. Tohoku J Exp Med 2020;252:133-41

4 Fukuda W, Hanyu T, Katayama M, et al. Incidence of hepatitis B virus reactivation in patients with resolved infection on immunosuppressive therapy for rheumatic disease: a multicentre, prospective, observational study in Japan. Ann Rheum Dis 2017;76:1051-6.

5 Watanabe T, Fukae J, Fukaya S, et al. Incidence and risk factors for reactivation from resolved hepatitis $B$ virus in rheumatoid arthritis patients treated with biological disease-modifying antirheumatic drugs. Int J Rheum Dis 2019;22:574-82.

6 Lee WM. Hepatitis B virus infection. N Engl J Med 1997;337:1733-45.

7 Lin T-C, Hashemi N, Kim SC, et al. Practice pattern of hepatitis B testing in rheumatoid arthritis patients: a cross-national comparison between the US and Taiwan. Arthritis Care Res 2018;70:30-8.

8 Watanabe R, Ishii T, Nakamura K, et al. Prevalence and time course of hepatitis B virus infection in patients with systemic lupus erythematosus under immunosuppressive therapy. Mod Rheumatol 2013;23:1094-100.

9 Watanabe $\mathrm{R}$, Ishii $\mathrm{T}$, Kobayashi $\mathrm{H}$, et al. Prevalence of hepatitis B virus infection in patients with rheumatic diseases in Tohoku area: a retrospective multicenter survey. Tohoku J Exp Med 2014;233:129-33.

10 Watanabe R, Ishii T, Harigae H. Pretreatment screening for hepatitis B virus infection in patients with systemic lupus erythematosus. Tohoku J Exp Med 2015;237:9-15. 